\title{
A COMPARATIVE STUDY BETWEEN HARMONIC SCALPEL HEMOSTASIS AND CONVENTIONAL HEMOSTASIS IN TOTAL AND SUBTOTAL THYROIDECTOMY
}

\author{
Mohammed Salim Mohammed*, Jasim D Saud ${ }^{\#}$, Mansour Amin Mohammed ${ }^{\$}$ \& \\ Mazin H Al-Hawaz ${ }^{\circledR}$ \\ "MB,ChB, Board Candidate. "MB,ChB, FICMS, CABS, Consultant Surgeon, Basrah General Hospital. \\ ${ }^{\$}$ MB,ChB, DS, CABS, MRCS, Lecturer, Dept. of Surgery, College of Medicine. ${ }^{@}$ MB,ChB, CABS, \\ DGS, FRCS, Prof. of General Surgery, Basrah Medical College., Basrah, IRAQ.
}

\begin{abstract}
Thyroid gland is highly vascularized organ, so good hemostasis during total or sub-total thyroidectomy is crucial to decrease the complications and to improve the outcome.

This study aimed to evaluate the advantages and disadvantages of using harmonic scalpel device in comparison with conventional hemostasis for total and subtotal thyroidectomy in terms of operative time, nerves injury, post-operative blood loss, hematoma development, hypocalcemia and length of hospital stay.

This study included 80 patients who underwent total or subtotal thyroidectomy. They were divided into two groups according to the type of hemostasis: conventional hemostasis group and harmonic hemostasis group. Different diseases were included (multinodular goiter, toxic goiter and malignant diseases).

The results showed that time of operation was significantly shorter in the harmonic hemostasis group (79.52 $\pm 14.98 \mathrm{~min})$ than conventional hemostasis group (100.92 $\pm 10.64 \mathrm{~min})$ with $p$ value 0.0001 , also post-operative blood loss was lower in harmonic hemostasis group $(52.5 \pm 26.23 \mathrm{ml})$ than conventional hemostasis group $(75.13 \pm 17.8 \mathrm{ml})$ with $p$ value 0.0001 . Other outcome such as recurrent laryngeal nerve injury, post-operative hematoma, post-operative hypocalcemia and length of hospital stay did not show significant difference between the groups.

In conclusion, using harmonic scalpel device in total or subtotal thyroidectomy reduced the operative time and post-operative blood loss, without any change in the incidence of nerve injury, hematoma, hypocalcemia and the length of hospital stay.
\end{abstract}

\section{Introduction}

Coiter has been recognized since $\checkmark$ earliest recorded history. The first mentioned goiter was in China as early as $2700 \mathrm{BC}$, and the first described thyroidectomy was done by Abulkasim Alzahrawi in $936 \mathrm{AD}^{1}$.

Early trials to treat thyroid enlargement and hyperactivity were associated with high mortality and morbidity due to asphyxia and hemorrhage. However, thyroid surgery continued with high mortality rate $(>40 \%)$; until the second half of the nineteenth century, as the first acceptable technique of standardized thyroid surgery which led to decrease mortality and morbidity was described by Theodor Kocher (1841-1917 AD) and Theodor Billroth (1829-1894 AD) ${ }^{2}$.
Thyroid gland has rich blood supply, so proper hemostasis in thyroidectomy is crucial to avoid intraoperative bleeding, to obtain good surgical field, and to prevent injury to laryngeal nerves and parathyroid glands ${ }^{3}$.

The conventional hemostasis technique in thyroid surgery relies on knot tying \pm electrocoagulation ${ }^{4}$. However, knot tying is time consuming and carries the risk of knot slipping; on the other hand, electrocautery implies potential risk of injuring surrounding tissues because of the heat ${ }^{5}$.

Since the development of Harmonic Scalpel (HS) by Ethicon in early 1990s (which was introduced for abdominal and laparoscopic procedures at the beginning), 
it has been used in thyroid surgery to ensure a bloodless field ${ }^{6}$. Some reports on the use of harmonic scalpel have shown advantages in thyroid surgery and significant reduction in operative time ${ }^{2,7}$. Harmonic scalpel devise uses vibration at $55-5 \mathrm{kHz}$ to simultaneously coagulate and cut tissue and seal $5 \mathrm{~mm}$ vessels. By transmitting the vibration to the tissue, this provokes hydrogen bonds of proteins rupture, and thus denatures protein to form a coagulum, which seals the vessels and provides hemostasis at low temperatures (about $80 \mathrm{C}^{\circ}$ ) in comparison with electrocautery. So it is safer for dissection near vital structures due to minimal lateral thermal tissue damage, minimal smoke formation, no electrical energy to or through patient and no neuromuscular stimulation ${ }^{7,8}$.

The aim of this study is to evaluate the harmonic scalpel advantages compared with conventional hemostasis (knot and tie ligation \pm electrocautery) in terms of operative time, nerves injury, postoperative blood loss, hematoma development, hypocalcemia and length of hospital stay.

\section{Materials and methods}

In this study, 80 patients with different thyroid diseases (multinodular goiter, toxic goiter and malignant diseases) were involved.

They underwent total or subtotal thyroidectomy in Basrah General Hospital from August 2015 to November 2016.

Patients with history of previous neck surgery, neck irradiation, preoperative vocal cord palsy, and those required lateral or central lymphadenectomy were excluded from this study.

Patients were selected according to the technique of hemostasis and classified into two groups: 38 (47.5\%) patients included in the group of conventional hemostasis (in which knot tying \pm electrocautery used for hemostasis), and 42 (52.5\%) patients included in the group of harmonic scalpel hemostasis.
All patients underwent checking of vocal cord mobility, thyroid function test, serum calcium, in addition to routine investigations one day before surgery.

Patients were divided into two hemostatic groups according to the surgeons' preference. The operations were done by two surgeons: one of them used the conventional hemostasis techniques and the other one used harmonic scalpel in hemostasis.

Surgery for all patients was done under general anesthesia with endotracheal tube; all patients positioned (reverse Trendelenburg) and draped in the classical way, collar neck incision 4-6 cm in length made, creation upper and lower subplatismal flap, incision made in the midline of deep cervical fascia and thyroid gland mobilized.

In the group of conventional hemostasis, the middle thyroid vein was ligated first using vicryl $2 / 0$, then superior thyroid vessels were ligated using double ligature of vicryl 0 or 1 , inferior pedicle and all other vessels ligated using vicryl $2 / 0$, with using of electrocautery for minimal oozing.

In the harmonic group, the middle thyroid vein coagulated and dissected by harmonic scalpel, then the superior pedicle and other vessels were coagulated and dissected using harmonic scalpel from Ethicon, thyroid tissue also dissected by harmonic scalpel.

In the total-thyroidectomy, the whole thyroid gland was resected, while in the sub-total thyroidectomy the isthmus was transected and each lobe resected to produce V-shaped surface, and this leaves 4-5 gm of thyroid tissue in each side, in the conventional hemostasis group, the divided surfaces were sutured for hemostasis, while in the harmonic hemostasis group the dissected surfaces were not sutured. Also care had been taken to preserve parathyroid glands.

Two Redivac drains were inserted and kept for 24-48 hours to calculate the amount of blood loss post operatively. 
Wound was closed in all patients with the classic way, vocal cord mobility was checked directly following extubation by the anesthesiologist.

The intra-operative parameters had been recorded including operative time (from skin cutting to skin closure), Recurrent Laryngeal Nerve (RLN) injury, and if in case the patient needed urgent tracheostomy.

Post-operative parameters were recorded from the time that the patient discharged from the theater to the time of hospital discharge and included development of hematoma or no, signs and symptoms of RLN injury (which include hoarseness of voice, shortness of breath, and checking of vocal cord mobility if there is any suspicion), serum calcium measuring for the patients that developed signs and symptoms of hypocalcemia (tingling and numbness in perioral area, Chvostek sign +ve and Trousseau signe +ve) and amount of blood collected in the drain for 24 or 48 hours.

Follow-up for six months was done for patients with hypocalcemia, recurrent laryngeal nerve injury, permanent nerve palsy considered when persisting more than six months after operation.
Data were analyzed using SPSS software version 18. Continuous variables data were reported as mean and standard deviation(SD), while Categorical variables reported using frequency distributions and chi-square test used in cases of low expected frequencies ( $p$ value $<0.05$ was considered significant).

\section{Results}

Mean age of the patients was 41.75 years (range 20-66 years), 59(73.8\%) of them were females and 21(26.2\%) were males.

The underlying diseases were: multinodular goiter (MNG) 47(58.75\%) patients, toxic goiter 28(35\%) patients, and malignant diseases 5(6.25\%) patients. Total thyroidectomy was done for $5(6.25 \%)$ patients (all of them with malignant diseases) and subtotal thyroidectomy was done for 75(93.75\%) patients, (table I shows the general demographic and pathological criteria of the groups studied).

The demographic criteria of each hemostatic group distributed almost equally, p values for all parameters were less than 0.05. Table II shows the demographic criteria according to the type of hemostasis.

Table I: General demographic criteria in the study group $(\mathbf{N}=\mathbf{8 0})$.

\begin{tabular}{|c|c|}
\hline Age (yrs.), M(SD) & $41.75(13.315)$ \\
\hline \multicolumn{2}{|l|}{ Gender } \\
\hline (female) & $59(73.8 \%)$ \\
\hline (males) & $21(26.2 \%)$ \\
\hline \multicolumn{2}{|c|}{ Underlying disease } \\
\hline Multi nodular goiter( MNG) & $47(58.75 \%)$ \\
\hline Toxic goiter & $28(35 \%)$ \\
\hline Malignant disease & $5(6.25 \%)$ \\
\hline \multicolumn{2}{|l|}{ The procedure } \\
\hline Total thyroidectomy & $5(6.25 \%)$ \\
\hline Subtotal thyroidectomy & $75(93.75 \%)$ \\
\hline \multicolumn{2}{|c|}{ Type of hemostasis } \\
\hline Conventional hemostasis & $38(47.5 \%)$ \\
\hline Harmonic hemostasis & $42(52.5 \%)$ \\
\hline
\end{tabular}


Table II: Demographic criteria according to the type of hemostasis.

\begin{tabular}{|l|c|c|c|}
\hline \multicolumn{1}{|c|}{ Variable } & Conventional Hemostasis & Harmonic hemostasis & P value \\
\hline $\begin{array}{l}\text { Age(years) } \\
\text { Mean (SD) }\end{array}$ & $42.08(13.649)$ & $41.45(13.164)$ & $>0.05$ \\
\hline Male & $10(26.3 \%)$ & $11(26.2 \%)$ & $>0.05$ \\
\hline Female & $28(73.7 \%)$ & $31(73.8 \%)$ & $>0.05$ \\
\hline MNG & $24(63.15 \%)$ & $23(54.76 \%)$ & $>0.05$ \\
\hline Toxic goiter & $12(31.57 \%)$ & $16(38.09 \%)$ & $>0.05$ \\
\hline Malignant & $2(5.3 \%)$ & $3(7.14 \%)$ & $>0.05$ \\
\hline Total thyroidectomy & $2(5.26 \%)$ & $3(7.14 \%)$ & $>0.05$ \\
\hline Subtotal thyroidectomy & $36(94.73 \%)$ & $39(92.85 \%)$ & $>0.05$ \\
\hline
\end{tabular}

The correlation between types of hemostasis and outcome:

Intra-operative parameters; the time of operation was significantly shorter in the group of Harmonic hemostasis than the group of conventional hemostasis: $79.52 \pm$ 14.89 minutes vs. $100.92 \pm 10.64$ minutes respectively with $\mathrm{p}<0.0001$ as shown in Table III.

Recurrent laryngeal nerve injury was not significant and occurred in one case $(2.63 \%)$ in the conventional hemostasis group vs. two cases (4.8\%) in the harmonic hemostasis group with $\mathrm{p}=0.586$ as shown in Table III; One case had bilateral RLN injury (from harmonic hemostasis group) and caused temporary vocal cord palsy that required tracheostomy which was removed within three months. Other two cases were unilateral and were temporary, recovered within three months.

Post-operative parameters; the amount of blood loss in the drain was lower in the harmonic hemostasis group than conventional hemostasis group, and was statically significant: $52.5 \pm 26.53 \mathrm{ml}$ vs. $75.13 \pm 17.8 \mathrm{ml}$ respectively with $\mathrm{p}<0.0001$ as shown in Table III.
Other post-operative parameters were not significant (Table III), and they include:

Post-operative hematoma which developed in one case (2.6\%) in conventional hemostasis group vs. three cases $(7.14 \%)$ in harmonic hemostasis group with $\mathrm{p}=0.355$ (Table III); and one case from each group was tension hematoma that required urgent surgical intervention for evacuation of hematoma to release the pressure on trachea and securing the hemostasis and ligation the source of bleeding, while the other two cases (from harmonic hemostasis group) were superficial hematoma and treated conservatively.

Hypocalcemia developed in two cases (5.3\%) in conventional hemostasis group and two cases (4.8\%) in harmonic hemostasis group with $\mathrm{p}=0.653$ (Table III). All cases were treated with calcium supplement, and all cases were temporary, that recovered within 6 months.

Hospital stay was approximately equal in both groups (1.39 day in the conventional hemostasis group vs. 1.36 day in the harmonic hemostasis group with $\mathrm{p}=0.844$ ) as shown in Table III below. 
Table III: Correlation between type of hemostasis and outcome

\begin{tabular}{|l|c|c|c|}
\hline Outcome & $\begin{array}{c}\text { Conventional } \\
\text { hemostasis }\end{array}$ & $\begin{array}{c}\text { Harmonic } \\
\text { hemostasis }\end{array}$ & P value \\
\hline Time of operation (min.), M(SD) & $100.92(10.645)$ & $79.52(14.89)$ & 0.0001 \\
\hline RLN injury & $1(2.6 \%)$ & $2(4.8 \%)$ & 0.538 \\
\hline Postoperative hematoma & $1(2.6 \%)$ & $3(7.14 \%)$ & 0.355 \\
\hline Hypocalcemia & $2(5.3 \%)$ & $2(4.8 \%)$ & 0.653 \\
\hline Blood loss in (ml), M(SD) & $75.13(17.8)$ & $52.5(26.23)$ & 0.0001 \\
\hline Hospital stay (days), M(SD) & $1.39(0.82)$ & $1.36(0.87)$ & 0.844 \\
\hline
\end{tabular}

\section{Discussion}

Thyroid gland is one of the highly vascularized organs, for it receives blood from inferior and superior thyroid arteries. Also its position which is adjacent to recurrent laryngeal nerves and parathyroid glands necessitates good hemostasis during thyroid surgery (especially for total and sub-total thyroidectomy) to avoid multiple complications starting from intraoperative bleeding that obscures surgery field and leads to accidental nerve injury ending by post-operative hematoma which is life threatening and can cause asphyxia ${ }^{2,3,9}$.

The conventional hemostasis technique uses knot and tie so can consume time. On the other hand, using the electrocautery in thyroid surgery can also cause adjacent nerves and parathyroid glands injury due to distal thermal effect ${ }^{2,4,10}$, therefore, the need for secure hemostasis with less time consuming becomes crucial.

Since the development of harmonic scalpel in 1990s, it has been used for thyroid surgery as hemostatic tool. Some researches were done for evaluating the benefits and risks of Harmonic in thyroid surgery $^{2,6,7,11,12}$.

In the present study, the type of procedure and underlying disease were distributed approximately equally in both hemostatic groups with no deference statistically (Tables II \& III) and so this will not affect the results.

In this study, it was found that using of harmonic scalpel significantly shortened the time of operation of both total and sub-total thyroidectomy by about $21 \mathrm{~min}$.
The results are approximately similar to that of Cannizzaro MA, et al $2014^{2}$ who showed decrease in the time of surgery by about 31 minutes in harmonic hemostatic group. Dun YF, et al $2013^{3}$ also showed shortening in the time of surgery by about 46 minutes. Groups of researches show similar result ${ }^{6-9}$.

In the present study, two Redivac drains were inserted for all the patients and were kept for 24-48 hours and the amount of blood drained was recorded. It was found that the amount of blood drained from the harmonic hemostasis group was lower than the conventional hemostasis group by about $22.6 \mathrm{ml}$. This result was similar to that of Cannizzaro MA, et al $2014^{2}$ who showed decrease in post-operative blood loss by $28.6 \mathrm{ml}$ in harmonic use as compared with the conventional hemostasis; Bangash $\mathrm{A}$, Khan $\mathrm{N}$ et al $2014^{13}$, also showed that blood in the drain was $28 \mathrm{ml}$ less in the harmonic hemostasis group than clamp-tie group; similar results shown in other studies ${ }^{6,9,11}$. One of the most serious complication in the total or sub-total thyroidectomy is recurrent laryngeal nerves injury, and this is a serious problem that causes vocal cord palsy which is mainly temporary injury that recovered within 6 months, and sometimes the nerve injury is permanent. When bilateral recurrent laryngeal nerves are injured, bilateral vocal cord palsy occurs, and thus tracheostomy is required. The present study shows no difference in incidence of RLN injury in both groups: one patient in the conventional hemostasis 
group and two patients in the harmonic hemostasis group. One patient had bilateral and required tracheostomy (from harmonic hemostasis group); RLN injury in all cases was temporary and recovered within three months. This result is approximately similar to that of other studies $^{3,8,14}$.

Hematoma developed postoperatively in four patients in this study; two of them required urgent surgical intervention to evacuate hematoma and secure hemostasis (one in each hemostatic group), two patients were treated conservatively (statistically not significant). This result is similar to the result of Cannizaro MA et $\mathrm{al}^{2}$, Ali SM et $\mathrm{al}^{9}$, and Vidinov KN et $\mathrm{al}^{10}$ but differs from result found by Ecker $\mathrm{T}$ et $\mathrm{al}^{8}$ study which showed a decrease in the incidence of post-operative hematoma by using harmonic scalpel for hemostasis

In the present study, four patients developed hypocalcemia postoperatively and were treated by calcium supplement and all the cases were temporary and recovered within six months.

Length of hospital stay was not affected by type of hemostasis.

\section{Conclusion}

From all the above results, it was found that using of harmonic scalpel in total or subtotal thyroidectomy reduced the time of surgery and decreased post-operative blood loss without changing the incidence of nerve injury or postoperative hematoma, hypocalcemia and without a change in the length of hospital stay.

\section{References}

1. Mercic MA, Kaplan EL, Gaz RD, Slough CM, et al ."History of Thyroid and Parathyroid Surgery" in: Radolph GW .editor. Surgery of Thyroid and Parathyroid Gland .Philadelphia: ELSEVIER; 2013.vol 1. P.03.

2. Cannizzaro MA, Bianco SL, Borzi L, Cavallaro A et al.: "The use of FOCUS Harmonic scalpel compared to conventional hemostasis (knot and tie ligation) for thyroid surgery: a prospective randomized study". Springer Plus 2014 (3)p.639.

3. Duan YF, Xue W, Zhu F , Sun D:" FOCUS harmonic scalpel compared conventional hemostasis in open total thyroidectomy a prospective Randomized study" .Journal of Otolaryngology Head and Neck Surgery 2016 42:62.

4. Siperstein AE, Berber E, Morhoym E. "The use of the harmonic scalpel vs conventional knot tying for vessel ligation in thyroid surgery". Arch Surg. 2002 Feb; 137(2):137-42.

5. Nenkov R, Radev K, Marinova E , Cvetkov N. et al. "The Harmonic Scalpel Application In Thyroid surgery" . JIMAB 2013.vol 19:408-411.

6. Aziz W, Khan MS, Assad S, Siddique G. "Suture-less Thyroidectomy Using Harmonic Scalpel versus Conventional Thyroidectomy: A Randomized Controlled Trial". JPMS 2016 vol.6(2):48-51

7. Sista F, Schietoroma M, Ruscitti C, Santis GD. et al." New Ultrasonic Dissector versus Conventional Hemostasis in Thyroid Surgery: A Randomized Prospective Study". JOURNAL OF LAPAROEND-OSCOPIC \& ADVANCED SURGICAL TECHNIQUES. 2012 22(3):220-224

8. Ecker T, Cavalho AL, Choe JH, Walosek G, Preuss KJ." Hemostasis in thyroid surgery: Harmonic scalpel versus other techniques-a meta-analysis". Otolaryngology-Head and Neck Surgery (2010) 143, 17-25

9. Ali SM, Khan JS, Khan MM. "Harmonic Scalpel vs. Knot tying in open Thyroidectomy “.Ann.Pak.Inst.Med.Sci.2014;10(1)50-53.

10. Vidinov KN, Sechanov TL. "Thyroid surgery: comparison between (ultrasonic scalpel- SonoSurg) and classic (clamp and tie) technique". JCEI 2015; 6(3):209-213.

11. Choe H, Jung KY, Kown SY, Woo JS. et al. "Usefulness of the Harmonic Scalpel in thyroid surgery". J Korean Thyroid Assoc. 2012 November 5(2): 138-142.

12. Regmi D, Bista M, Shrestha S, KC T. "Comparison of surgical outcomes of Ultrasonic technique (Harmonic Focus) with conventional technique in open hemithyroidectomy". Journal of Kathmandu Medical College, Vol. 2,No. 4, Issue 6, Oct- Dec., 2013:175-180.

13. Bangash A, Khan N, Azeem I, Sasiq M. "Technique of clamp- tie thyroidectomy versus Harmonic focus. Is there a need for technology?" Journal of The Scientific Society, vol. 41/Issue 1/ January-April 2014:10-15.

14. Ferri E, Armato E, Spinato G,Spinato R. "Focus Harmonic Scalpel Compaired to conventional Hemostasis in Open Total Thyroidectomy : A Prospective Randomized Trial".In J Otolaryngology volume 2011: 357195. 